\title{
Migrações e a dispersão espacial da população nas Regiões de Influência das principais metrópoles brasileiras
}

\author{
Carlos Lobo* \\ Ralfo Matos**
}

\begin{abstract}
A segunda metade do século passado é central na análise da distribuição espacial da população brasileira. Em poucos anos, diante do processo de urbanização e industrialização do país, resultado em boa medida da dinâmica migratória interna, grande parte da população e das atividades econômicas passou a se concentrar nos principais centros urbanos, sobretudo nos grandes aglomerados metropolitanos. Contudo, desde o final da década de 1970, alguns autores já aventavam a hipótese de reversão da polarização no Brasil, tal como formulado pelos modelos aplicados nos países desenvolvidos. Afora as recorrentes controvérsias sobre o tema, que acarretaram a difusão de expressões como "reversão da polarização", "desconcentração concentrada", "desenvolvimento poligonal", entre outras, essa pesquisa tem como objetivo principal avaliar a atual magnitude da dispersão espacial da população brasileira, tendo como base as Regiões de Influência das principais metrópoles do país, conforme recorte proposto pelo IBGE. Para tanto, foram utilizadas as bases referentes aos Censos Demográficos de 1991 e 2000, que possibilitaram identificar os fluxos de população. Mesmo que os resultados não sejam conclusivos para todas as Regiões de Influência, no caso específico de São Paulo os valores para os estoques e fluxos, associados à dimensão distância, indicam a intensificação na ocupação dos espaços fora dos limites das Regiões Metropolitanas. $O$ crescimento da emigração para a Região de Influência da metrópole paulista parece confirmar uma espécie de "dispersão polinucleada", observando-se claros sinais de expansão no interior da Região de Influência, o que sugere o fortalecimento de determinados centros regionais e um maior dinamismo da economia local.
\end{abstract}

Palavras-chave: Migração. Dispersão espacial. Regiões de Influência.

\section{Introdução}

Uma das questões de interesse dos estudos regionais refere-se ao suposto processo de desconcentração espacial da população e das atividades econômicas. Afora as recorrentes controvérsias, que resultaram na difusão de expressões como

\begin{abstract}
"reversão da polarização", "desconcentração concentrada", "desenvolvimento poligonal", há pelo menos um relativo consenso acerca das evidências empíricas de queda no ímpeto de crescimento populacional dos grandes centros metropolitanos brasileiros nas últimas décadas do século passado. Embora os processos de urbanização e
\end{abstract}

\footnotetext{
* Doutor em Geografia pelo IGC/UFMG, professor adjunto do Departamento de Geografia da UFSJ.

** Doutor em Demografia pelo Cedeplar/UFMG, professor associado do Departamento de Geografia do IGC/UFMG.
} 
metropolização no Brasil sejam recentes, os dados referentes aos dois últimos Censos Demográficos parecem confirmar uma tendência de dispersão espacial da população, mesmo que os principais centros metropolitanos tenham mantido sua expressão demográfica regional e continuado a atrair expressivos contingentes populacionais.

Além das contribuições da economia regional, esse debate requer ainda novas evidências sobre os efeitos da distribuição espacial da população, notadamente no que se refere aos movimentos migratórios. No âmbito da Geografia, são raros os trabalhos sobre migrações internas, principalmente aqueles que utilizam informações censitárias para estimar os movimentos espaciais da população. A análise espacial dos fluxos migratórios permite reconhecer dimensões ainda pouco exploradas na abordagem convencional nos estudos sobre o processo de desconcentração ou dispersão espacial da população, praticamente restrita à Demografia e à Economia. É por essa lacuna que o presente trabalho pretende trilhar.

O objetivo principal é avaliar a atual magnitude da dispersão espacial da população brasileira, tendo como recorte espacial de análise as Regiões de Influência das principais metrópoles do país, estabelecidas pelo IBGE. Diante desse propósito, algumas questões podem ser exploradas: as evidências trazidas pelos dados censitários das últimas duas décadas demonstraram uma dispersão espacial a partir dos principais aglomerados metropolitanos? Haveria um rearranjo dos fluxos migratórios no interior das Regiões de Influência das principais cidades brasileiras? Seria a dispersão espacial evidenciada pela intensificação e difusão da emigração metropolitana? Ou essa dispersão é muito incipiente, estando ainda restrita às periferias imediatas das metrópoles?

No levantamento das evidências empíricas, foram utilizadas as bases referentes aos dois últimos Censos Demográficos, o que possibilitou identificar os movimentos migratórios intermunicipais. O pressuposto principal é de que essa dispersão se materializa pelo crescimento no volume dos fluxos de população migrante das Regiões Metropolitanas (centro dispersor) para os demais municípios de cada uma das Regiões de Influência, considerada a distância envolvida nos vetores migratórios.

Cabe, contudo, expor algumas considerações iniciais. Uma primeira refere-se à adoção da Região Metropolitana (RM) como centro de dispersão. Ainda que outras pesquisas tenham considerado o núcleo e a periferia entidades distintas e separadas, optou-se em manter a unidade dessas regiões, tendo em vista tratar-se, em geral, de espaços com razoável contiguidade física e forte nível de interdependência, tanto econômica quanto social e política. Mesmo que existam diferenças quando comparadas as diversas Regiões Metropolitanas no Brasil, resultado de critérios distintos na delimitação e definição dos municípios que integram cada uma delas, parece pouco razoável não considerar as RMs em sua integralidade. Veja os exemplos de São Paulo/Guarulhos, Rio de Janeiro/Niterói, Belo Horizonte/Contagem, etc. Embora sejam unidades políticas e administrativas distintas, são espaços altamente articulados, cujas inter-relações justificaram o próprio estabelecimento das Regiões Metropolitanas.

Outro ponto diz respeito à não adoção de um único núcleo polarizador. Em estudos anteriores, foi comum a utilização de São Paulo, seja o município, RM ou Estado, como centro aglutinador, a partir do qual era avaliada a suposta desconcentração espacial. Contudo, parece pouco plausível supor que a aceleração do crescimento demográfico das Regiões Metropolitanas de Belo Horizonte, Curitiba, Recife e Salvador, por exemplo, possa representar um quadro de desconcentração espacial da população brasileira. Além do mais, São Paulo e região mantiveram sua relevância demográfica e econômica e ainda exercem forte influência em grande parte do território nacional. A análise centrada nas Regiões de Influência das principais Regiões Metropolitanas do país pode conduzir a resultados mais consistentes e coerentes com a realidade atual. Mais que uma ampliação de escala, essa abordagem regional permite identificar processos espaciais que ocorrem em níveis hierárquicos inferiores, mais próximos das relações que se estabelecem entre os cen- 
tros regionais e os demais municípios de sua área de influência. ${ }^{1}$

Ainda que não seja objetivo deste trabalho investigar os fatores sociais, políticos ou econômicos determinantes da dispersão espacial, a produção e divulgação de indicadores específicos podem ser úteis à elaboração e proposição de políticas públicas necessárias à redução das desigualdades regionais no país. Em várias circunstâncias, a redistribuição da população deixa de ser uma mera consequência de determinados processos espaciais, tornando-se catalisadora de profundas mudanças na realidade regional, a exemplo do papel da migração na dinamização de São Paulo ou do Centro-Oeste brasileiro.

\section{Reversão da polarização, desconcentração concentrada e desenvolvimento poligonal}

Uma obra de referência na discussão sobre o processo de reversão da polarização foi elaborada por Richardson (1980). Para esse autor, o crescimento continuado da concentração das atividades econômicas não leva a um perpétuo aumento da eficiência. Os benefícios marginais derivados da escala urbana e da concentração produtiva tendem a diminuir a partir de certo tamanho de população. Os custos médios de prover infraestrutura física, serviços públicos e administração governamental local aumentam em termos per capita com o crescimento da cidade. A relação custo-benefício altera-se a favor de custos crescentes. Para Richardson, o ponto de inflexão médio e os custos sociais marginais refletem o começo de crescentes deseconomias de aglomeração, que ocorrem em função do incremento da congestão e contaminação (em conjunto com os fatores sociais tais como aumento da criminalidade e da marginalidade), da elevação no preço médio da terra (que passa a sofrer concorrência entre usos alternativos de solo) e do trabalho (aumento do custo de vida devido aos custos crescentes de transporte e habitação, explicados em parte pelas altas do preço da terra).

Para Redwood III (1984), as deseconomias caracterizam-se pela mudança de tendência de polarização espacial na economia nacional, a partir da qual ocorreria a dispersão para fora da região central. Esse processo acontece a partir de uma sequência de fases: no início haveria um processo bem definido de concentração econômica, quando se estabelecem um centro e uma periferia; em sequência ocorreriam transformações estruturais na área central, em que os núcleos adjacentes passariam a apresentar crescimento mais acelerado do que o centro; o terceiro estágio marcaria o início do processo de reversão da polarização, quando haveria uma dispersão ampliada; na sequência a dispersão também atingiria os centros secundários; e finalmente, a área central começaria a perder população. ${ }^{2}$ O crescimento demográfico e econômico das cidades secundárias reflete uma combinação de diversos fatores, que, em várias circunstâncias, exigem a intervenção pública na economia local (REDWOOD III, 1984).

Richardson, todavia, para além da expansão das cidades secundárias no entorno do core metropolitano, afirma que a difusão do crescimento inter-regional é uma condição inerente ao processo de reversão da polarização. ${ }^{3}$ De acordo com esse autor, a

\footnotetext{
1 Outro aspecto que também deve ser mencionado é a reduzida série histórica dos dados referentes aos movimentos migratórios. Pela necessidade de utilização dos fluxos intermunicipais, a análise restringiu-se aos dois quinquenios dos últimos intervalos censitários (1986/1991 e 1995/2000). Ainda que a identificação de tendências muito definidas em duas contagens consecutivas seja inconclusiva, trata-se de um período bastante peculiar. Essas décadas representam o momento de forte desaceleração no ritmo de crescimento populacional das principais metrópoles brasileiras.

2 Na literatura econômica, como indicado por Lo e Salih (1980), são listadas as seguintes condições para a ocorrência do processo de reversão da polarização: existência de pleno emprego no espaço urbano (o que pode fomentar os fluxos migratórios procedentes de áreas rurais); aparecimento de deseconomias de aglomeração (o que faria com que novos empreendimentos buscassem as regiões periféricas); ocorrência de efeitos de espraiamento em larga escala; e aumento da complexidade organizacional nas atividades empresariais.

3 Richardson analisou os casos do Japão e da Coréia, onde teria verificado o processo de reversão da polarização. Contudo, a experiência americana, com a perda expressiva de população das grandes cidades do Nordeste e o grande crescimento dos centros do Sul do país, é aquela que mais se aproxima do modelo proposto.
} 
Reversão da Polarização [RP] pode ser definida como o ponto de inversão, quando as tendências de polarização espacial na economia nacional dão lugar a um processo de dispersão espacial fora da região central em outras regiões do sistema. [...] Esse processo de dispersão inter-regional é a principal característica da RP. (RICHARDSON, 1980, p.67-68, tradução nossa).

Talvez seja exatamente essa dispersão inter-regional o principal aspecto controverso sobre a ocorrência da reversão da polarização no Brasil. No âmbito da análise regional, há várias tentativas de aplicação desses modelos para o caso brasileiro, cujas particularidades estruturais e setoriais vão oferecer dificuldades adicionais à interpretação desse fenômeno.

Um dos primeiros trabalhos que avaliou a possível reversão da polarização no Brasil foi realizado por Townroe e Keen (1984). Os autores consideram que esse processo verifica-se a partir do ponto em que a concentração da população urbana na região central começa a declinar, de modo que a razão entre a população da maior cidade e a população total do Estado começa a decrescer. Townroe e Keen calculam quatro índices de reversão da polarização: porcentagem da população urbana localizada na área metropolitana; mudança na porcentagem da população urbana localizada na área metropolitana; porcentagem do crescimento da população urbana absorvido pela área metropolitana; e diferença da taxa média anual de crescimento populacional entre a área metropolitana e o restante do Estado. Esses autores ainda sugerem certa dualidade dos fatores que levam à concentração das atividades econômicas, representados pelo papel concentrador de determinadas forças sociais e econômicas, que a partir de um ponto passariam a atuar na direção oposta: da desconcentração. A transição demográfica, os graus de desigualdade social e econômica, os padrões de desenvolvimento rural e as formas institucionais e sociais de difusão de informações e inovações podem incrementar ou não a concentração na distribuição da população urbana.

Redwood III (1984) também apresentou evidências sobre o caso brasileiro. Com a constatação da perda da participação do Estado de São Paulo a partir do final da década de 1950, o autor acredita que estaria em curso um processo de desconcentração das principais áreas metropolitanas, favorecendo os centros secundários mais próximos. Ao trabalhar com as principais tendências demográficas e a localização da atividade industrial, foram encontradas evidências de que os processos de suburbanização, descentralização urbana e reversão da polarização se difundiam em todo o sistema urbano (REDWOOD III, 1984). ${ }^{4}$

É essencial, na interpretação de Redwood III, a atenção dirigida às necessidades das cidades secundárias, que cumprem papel fundamental na eficiência econômica e no desenvolvimento regional. No exame do desenvolvimento econômico regional, o autor sugere que certos tipos de atividade industrial tendem a naturalmente se localizar nessas cidades. As indústrias de bens intermediários baseadas em recursos naturais (química, plásticos, madeira, papel e metalurgia, incluindo aço) podem estar localizadas próximas de grandes cidades, de modo a reduzir custos de transportes, valendo-se da proximidade dos mercados. Outro grupo de indústrias se dirige às cidades secundárias para se servir dos mercados locais protegidos da concorrência externa, dados os custos de transportes relativamente altos. Alguns serviços de maior magnitude e mais especializados, como universidades, hospitais e algumas atividades comerciais, procuram se instalar em centros médios.

Ainda que possam parecer bastante atraentes, as proposições sobre o possível pro-

\footnotetext{
4 Uma constatação feita por Redwood III foi a redução na participação do Estado de São Paulo na produção industrial nacional, que passou de 48,3\%, em 1970/75, para 47,3\%, em 1980. O autor também chama atenção para a queda na proporção do emprego industrial na Região Metropolitana de São Paulo, que reduziu de 70,7\%, em 1959, para 63,3\%, em 1977/79. Na área de influência da RMSP, a tendência foi inversa, com valores relativos que subiram de $29,3 \%$ para $36,4 \%$, no mesmo período.
} 
cesso de reversão da polarização no Brasil sofreram inúmeras críticas. As controvérsias vão desde as evidências empíricas, até o tipo de variáveis e a metodologia utilizada. Azzoni (1986), por exemplo, critica o fato de o tamanho da cidade ser considerado indicador de economias aglomerativas. Ao admitir que as vantagens aglomerativas estão presentes no ambiente urbano, a exemplo da linha de polarização psicológica e do transporte de ideias, é imprescindível considerar a região capaz de gerar um campo de atração sobre novos investimentos. A ideia essencial é que a atração regional transcende o ambiente urbano, embora os custos locacionais sejam essencialmente urbanos. Para Azzoni, é no mínimo apressada a suposição de que haveria um processo de reversão da polarização no Brasil. Pelo contrário,

as evidências indicam que, longe de constituirse um sinal de reversão da polarização, o fenômeno observado em São Paulo estaria mais próximo de um espraiamento da indústria dentro da área mais industrializado do país, em um processo do tipo "desconcentração concentrada". Seria aproximadamente um tipo de suburbanização das atividades industriais em âmbito mais abrangente, o que é possível pelas oportunidades abertas pelo desenvolvimento tecnológico, em um sentido amplo, para separação das atividades produtivas das atividades de comando empresarial. (AZZONI, 1986, p.126).

Azzoni acredita que a Região Metropolitana de São Paulo não deve ser considerada referência para análise das alterações espaciais no Estado paulista, mas sim a ação de um campo aglomerativo que inclui um conjunto de cidades, num raio de aproximadamente $150 \mathrm{~km}$ da Região Metropolitana. Segundo o autor, esse campo exerce uma forte força de atração sobre os investimentos industriais e, consequentemente, sobre a população. À medida que aparecem novos avanços tecnológicos, esse campo aglomerativo amplia-se e reduz o próprio poder de atração do núcleo central.

Para Diniz (1993), o "espraiamento" industrial brasileiro não ocorreu apenas dentro do limitado raio de $150 \mathrm{~km}$ da área metropolitana de São Paulo. Após a incontestável concentração econômica e demográfica verificada até final da década de
1960, iniciou-se, em um primeiro momento, o processo de reversão dessa polarização. Entretanto, o processo de desconcentração não teria ocorrido de modo ampliado, mas sim em espaços seletivos bem equipados e ricos em externalidades no país, refletindo, sobretudo, o espraiamento para o interior de determinados Estados. Em uma segunda fase, ocorreria a relativa reconcentração no polígono definido pela região formada por Belo Horizonte-Uberlândia-Londrina/ Maringá-Porto Alegre-Florianóplis-São José dos Campos-Belo Horizonte.

Ao contestar alguns dos pressupostos e os resultados apresentados por Azzoni, Diniz (1993) incorpora uma série de outros aspectos, além das economias de aglomeração. Desses aspectos, destacam-se: a distribuição espacial dos recursos naturais; o papel do Estado; o processo de unificação do mercado nacional e suas implicações para a concorrência intercapitalista e as estruturas produtivas regionais; as economias de aglomeração; e a concentração regional da pesquisa e renda, que cria obstáculos à desconcentração regional da indústria. Ao avaliar o processo recente de desenvolvimento industrial e desconcentração econômica, o autor reforça essa dualidade, afirmando que o Brasil verdadeiramente dinâmico está restrito a um "polígono" que abrange o Sul e parte do Sudeste do país, estendendo-se de Belo Horizonte a Porto Alegre, ficando de fora o Rio de Janeiro e a maior parte do território brasileiro. Nesse espaço,

é mais apropriado considerar o Brasil como um caso de desenvolvimento poligonal, onde um número limitado de novos pólos de crescimento ou regiões tem capturado a maior parte das novas atividades econômicas. O resultado está longe de ser uma verdadeira desconcentração, especialmente porque os novos centros estão no próprio Estado de São Paulo ou relativamente próximos dele. (DINIZ, 1993, p.35).

Diniz reforça a abrangência espacial restrita da suposta reversão da polarização para o caso brasileiro. De acordo com o autor,

não parece que esta tendência de reversão em sentido amplo continuará até o final do século. Ao contrário, a grande ênfase em indústrias de alta tecnologia e o relativo 
declínio e fracasso das políticas regionais e do investimento estatal abrem uma terceira possibilidade. Nesta o processo de desconcentração será enfraquecido e o crescimento tenderá a se circunscrever ao estado de São Paulo e ao grande polígono em torno dele. Estamos chamando este processo de aglomeração poligonal. (DINIZ, 1993, p.54).

As conclusões de Diniz (1993) introduzem a ideia de que o resto do país ficaria à margem dos efeitos cumulativos do desenvolvimento do core paulista. Contudo, o autor não trabalha com uma temporalidade prospectiva de longa duração e, assim, não vislumbra outras possibilidades de desenvolvimento econômico para o resto do país fora do padrão técnico-moderno prefigurado pelas sociedades de consumo dos países desenvolvidos, o qual, evidentemente, se encontra presente nos grandes centros urbanos do país (MATOS, 2003).

Nesse nível de análise, as redes geográficas e particularmente as redes urbanas mostram-se mais eficientes à análise econômico-espacial do que as visões duais do território brasileiro, presentes em recortes espaciais como o do polígono do desenvolvimento de Diniz, que se ressente da ausência da noção moderna de rede geográfica. As redes podem expressar dimensões abstratas, mas comumente traduzem materialidades espaciais. São espaços e subespaços em movimento; lugares articulados por fluxos multivariados; fluxos de pessoas, capitais, informações, ideias e culturas. As redes mais importantes estão carregadas de técnica e história social, sendo, portanto, construções dinâmicas relativamente duráveis. As redes urbanas, por exemplo, são depositárias de estruturas sociais pretéritas e futuras, tradicionais ou modernas, que dão forma e sentido à vida de milhares de pessoas, famílias e instituições. ${ }^{5}$

Matos (1995b) também acredita que importantes mudanças no padrão de distribuição espacial da população estão em curso, sem se conhecer, no entanto, qual é o verdadeiro alcance desse fenômeno, e se as explicações existentes abrangem todos os casos. É seguro afirmar que as pessoas, tanto quanto as atividades, reagem aos impactos das deseconomias de aglomeração buscando localizações alternativas.

A migração pode responder claramente aos fatores de expulsão do meio urbano (notadamente aos custos de moradia e à escassez de emprego), mas pode também se associar a outro grupo de causas, não econômicas, relacionadas à melhoria da qualidade de vida e/ou busca de amenidades, e ao retorno às localidades de origem após a aposentadoria. É indiscutível, portanto, que boa parte da expansão da urbanização do país nas últimas décadas deriva dos efeitos multiplicadores de espraiamento da concentração urbana e industrial do Sudeste. Esse processo estimulou o adensamento da rede urbana e os vínculos de complementaridade entre as centralidades.

A suposição de que a realidade brasileira possa se enquadrar no modelo analítico da reversão da polarização, ou mesmo em uma mudança de tendência demográfica de longo prazo, ainda é prematura. Acrescenta-se o fato de as mudanças recentes na distribuição da população e na estrutura econômica nacional terem ocorrido de forma bastante acelerada, diferente do que aconteceu em boa parte dos países desenvolvidos. Dessa forma, como salienta Matos (1995b), não parece plausível afirmar categoricamente sobre um amplo processo de reversão da polarização

\footnotetext{
${ }^{5}$ As redes urbanas podem ser expressas mediante técnicas que combinam um grande número de dados econômicos, sociais e geográficos, preferentemente transcritos em intensidades variáveis de fluxos entre as localidades. O dado populacional está sempre presente nas formulações teóricas e é utilizado em qualquer técnica de regionalização, não raro substituindo variáveis de fluxo inexistentes. Sobre os significados da população enquanto variável-controle, especialmente das populações em movimento, convém observar que elas não só exprimem a sociedade, a cultura e a ação política, real ou virtual, mas também impactam os ambientes onde se reproduzem, por constituir força de trabalho e mercados de consumo, fatores-chave para a geração de riqueza. Ademais, o estudo das populações, sobretudo com base em dados censitários, permite conhecer em detalhes diversas características dos fluxos de pessoas entre as localidades, pré-requisito para a formação de redes geográficas e redes sociais (MATOS, 2003).
} 
ou de desconcentração espacial. É bem provável que o país esteja passando por um ciclo de descompressão do crescimento urbano central, no qual os movimentos migratórios internos assumem importante papel explicativo.

\section{Fluxos migratórios e a dispersão espacial da população}

É importante destacar que a relação entre a migração e a estruturação do espaço não é tema novo na literatura. Quando Ravenstein (1980) formulou suas teses sobre os movimentos migratórios, apresentava-se explicitamente a relação entre as atividades econômicas e os deslocamentos espaciais da população. As principais regularidades encontradas pelo autor compreendiam a distância, os movimentos por etapas, a configuração das correntes e contracorrentes, a predominância da migração feminina e também o fato de que as migrações tendiam a gerar movimentos sucessivos a partir de áreas próximas a um centro industrial ou comercial. 6

Quase um século mais tarde, Lee (1980) retomou as formulações de Ravestein, incorporando informações a respeito dos movimentos internos nas sociedades de capitalismo tardio. $\mathrm{Na}$ interpretação desse autor, a decisão de migrar está vinculada a uma decisão racional entre os chamados fatores positivos e negativos nas áreas de origem e destino. Lee também acredita que a decisão de migrar nunca é completamente racional. Dessa forma, é natural que pessoas distintas sejam afetadas de maneira diferente por uma série de obstáculos ou incentivos à possibilidade de migrar.

Singer (1973), contudo, considera a migração um reflexo da estrutura e dos mecanismos de desenvolvimento do sistema capitalista, cujo motor principal é o acirramento das desigualdades regionais. Para o autor:
É claro que qualquer processo de industrialização implica uma ampla transferência de atividades (e, portanto, de pessoas) do campo às cidades. Mas, nos moldes capitalistas, tal transferência tende a se dar a favor de apenas algumas regiões em cada país, esvaziando as demais. Tais desequilíbrios regionais são bem conhecidos e se agravam na medida em que as decisões locacionais são tomadas tendo por critério apenas a perspectiva da empresa privada. (SINGER, 1973, p. 222)

Ao analisar a migração, Singer identifica os chamados "fatores de atração" e os "fatores de expulsão". Os primeiros referem-se à necessidade de mão de obra decorrente do crescimento da produção industrial e da expansão do setor de serviços urbanos, que funcionam como forças de concentração espacial. Os fatores de expulsão podem ser divididos em: "fatores de mudança", decorrentes da penetração do capitalismo no campo e da adoção de um sistema poupador de mão de obra; e os "fatores de estagnação", associados à pressão demográfica sobre a disponibilidade de terras. Para Singer, a distinção entre áreas de emigração (sujeitas aos fatores de mudança) e de estagnação permite visualizar melhor suas consequências. As regiões de mudança perdem população, mas a produtividade aumenta, o que permite, pelo menos em princípio, uma melhora nas condições de vida locais. Já as áreas de estagnação apresentam deterioração da qualidade de vida, funcionando às vezes como "viveiros de mão de obra" para os latifundiários e as grandes empresas agrícolas.

Nessa mesma perspectiva estruturalista, há, tanto na economia como na demografia, vários autores que expressam a migração como mobilidade, estreitamente vinculada à criação, expansão e articulação dos mercados de trabalho do país. O desenvolvimento desigual do sistema capitalista faz com que a população se distribua seguindo a mesma lógica de intensificação dos espaços eco-

\footnotetext{
6 Para Ravenstein (1980, p. 26), as grandes cidades "proporcionam facilidades tão extraordinárias à divisão e à combinação do trabalho, ao exercício de todas as artes e à prática de todas as profissões que, a cada ano, um número maior de pessoas nelas possa habitar." Para o autor, outros aspectos que também induzem a migração são as facilidades educacionais, a salubridade do clima ou a carestia de vida.
} 
nômicos, formando grandes reservatórios de mão de obra. Apesar de seu mérito, boa parte dessas teses responde apenas parcialmente às causas mais dinâmicas e específicas da migração, não vinculada apenas às necessidades estruturais do sistema capitalista. Além disso, tais formulações, em geral, ignoram as vantagens comparativas e as potencialidades externas que têm transformado os espaços de destino. Poucos avaliam o peso da migração de origem urbana, e quase nunca consideram a migração de retorno (MATOS, 1995b). Também investem de modo insuficiente no entendimento dos efeitos positivos que a migração pode gerar na dinamização das regiões de destino, no que diz respeito à oferta de mão de obra qualificada, a certas possibilidades de novos investimentos e de intercâmbio técnico, por exemplo. Nesse sentido, mais que um indicador de concentração ou dispersão das atividades econômicas, a migração reflete processos sociais mais amplos, cujas causas e consequências vão além dos aspectos estruturais da economia. ${ }^{7}$

Em face das recorrentes controvérsias sobre o processo de dispersão espacial da população, associado à ideia de reversão da polarização e/ou de desconcentração espacial, alguns pontos dessas definições devem ser destacados no desenvolvimento de determinados pressupostos e hipóteses deste trabalho. Se o modo como são organizados os elementos do espaço pode ser visto como um resultado histórico da atuação dos atores sociais, os fluxos de informação, capitais e pessoas, por exemplo, permitem e alimentam o dinamismo das formas e funções dos elementos que compõem e caracterizam o espaço. Para
Santos (1997), a necessidade de fluidez é uma das mais importantes características do mundo atual que é, ao mesmo tempo, causa, condição e resultado.

Essa condição de fluidez é particularmente relevante aos estudos sobre as migrações internas, que por definição envolvem o movimento de populações no espaço, em determinado intervalo ou em pontos definidos no tempo. São, por essência, fluxos que se manifestam e materializam no espaço. Esses contingentes de migrantes que se deslocam no espaço são não apenas resultado de uma realidade social e/ou condição econômica momentânea, mas também causa para outros fluxos, envolvendo, por exemplo, investimento, tecnologia e experiência profissional. Se a análise dos fluxos migratórios é recorrente no estudo demográfico, são raros os trabalhos que incorporam diretamente a dimensão distância como elemento efetivo da distribuição espacial da população.

Embora Ravenstein (1980) já tivesse indicado a predominância dos movimentos de curta distância e a ocorrência do que denominou de correntes migratórias contrárias e o estabelecimento de etapas de migração, várias possibilidades de análise extraídas a partir da variável distância ainda são pouco exploradas. ${ }^{8}$

\section{As Regiões de Influência das Cidades (Regics) do IBGE}

De acordo com o próprio IBGE, a delimitação das Regiões de Influência das Cidades (Regics) dá continuidade à tradição de estudar a rede urbana brasileira e visa construir um quadro nacional, apontando

\footnotetext{
7 Na discussão sobre os fatores que atuaram na quebra do padrão concentrador, vários autores chamam atenção para o perfil de desenvolvimento rural e urbano, as formas institucionais e sociais de difusão de informações e inovações, a inserção tardia ou avançada na transição demográfica e os graus de desigualdade regional. De acordo com Matos (2003), novas abordagens devem levar em conta as alterações recentes no padrão migratório brasileiro, marcado pela perda de primazia dos fluxos do campo para a cidade e pela dinamização da rede urbana. Em grande parte, essas mudanças respondem à difusão de determinadas externalidades positivas na periferia e novos fluxos migratórios podem se reorientar espacialmente, reagindo a fatores de atração presentes nas cidades secundárias.

8 De acordo com Renner e Patarra (1991), um dos aspectos enfatizados nos estudos das migrações tem sido a distância percorrida no ato de migrar. Em várias pesquisas verificou-se que a migração ocorre predominantemente a curta distância e que o volume diminui quando a distância ao centro aumenta. $\mathrm{Na}$ análise das distâncias percorridas por uma corrente migratória, tem sido enfatizado, em várias circunstâncias, o que se convencionou a chamar de variáveis intervenientes.
} 
as permanências e as modificações registradas. Os estudos anteriores, que definiram os níveis da hierarquia urbana e estabeleceram a delimitação das regiões de influência das cidades brasileiras, foram realizados pelo IBGE, em 1966, 1978 e 1993, a partir de questionários que investigaram a intensidade dos fluxos de consumidores em busca de bens e serviços. A atualização, realizada em 2007 e divulgada em 2008, retoma a concepção utilizada nos primeiros estudos elaborados pelo IBGE, que resultaram na divisão do Brasil em regiões funcionais urbanas de 1972. Nessa proposta foi inicialmente estabelecida uma classificação hierárquica dos centros metropolitanos do país. Em seguida, foram delimitadas suas áreas de atuação, denominadas Regiões de Influência (RI). Nesse estudo privilegia-se a função de gestão do território, como sugerido por Corrêa (1995), segundo o qual o centro de gestão do território "é aquela cidade onde se localizam, de um lado, os diversos órgãos do Estado e, de outro, as sedes de empresas cujas decisões afetam direta ou indiretamente um dado espaço que passa a ficar sob o controle da cidade através das empresas nela sediadas."

Duas etapas metodológicas são centrais nessa nova Regic: a definição hierár- quica dos centros de gestão do território; e a delimitação de sua região de influência. De modo simplificado, a classificação de hierarquia na rede de cidades leva em conta dois níveis de centralidade: a gestão federal, avaliada a partir da existência de órgãos dos Poderes Executivo e Judiciário federais; e a gestão empresarial, bem como a presença de diferentes equipamentos e serviços (comércio e serviços, instituições financeiras, ensino superior, saúde, Internet, redes de televisão aberta e conexões aéreas). Classificados em seis níveis de hierarquia, conforme sua posição no âmbito da gestão federal e empresarial, integram o conjunto final 711 centros de gestão do território, como representado na Figura 1.

A intensidade das ligações entre as cidades permitiu estabelecer suas áreas de influência e a articulação das redes no território. Para investigar a articulação dos centros de gestão, foram considerados os eixos de gestão pública e de gestão empresarial, complementados pelos serviços de saúde. As áreas de influência dos centros foram delineadas a partir da intensidade das ligações entre as cidades, com base em dados secundários e informações obtidas por questionário específico da pesquisa, possibilitando identificar 12 redes de primeiro nível.

FIGURA 1

Etapas da definição dos Centros de Gestão do Território

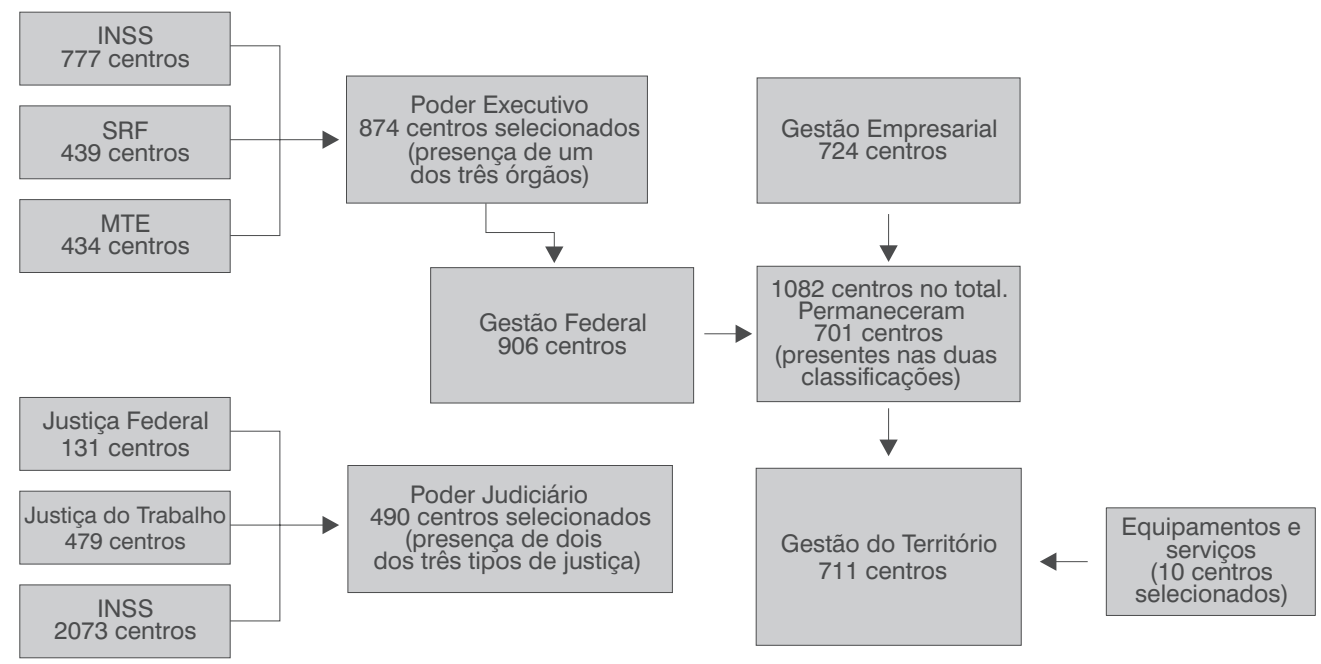

Fonte: IBGE (2008) 
Afora o mérito na delimitação regional proposta pelo IBGE, nesse trabalho foram implementadas algumas adaptações metodológicas necessárias para a definição das unidades espaciais de análise. Uma delas refere-se à inclusão da rede de influência de Uberaba na Regic de São Paulo e não de Belo Horizonte. Essa modificação se justifica pela descontinuidade espacial gerada na conformação do limite da Regic proposta pelo IBGE, que separava as áreas de influência de Uberlândia e Uberaba.
Outra alteração foi a fusão das Regics de Brasília e Goiânia, que representam espaços altamente articulados social e economicamente. Em função de sua posição peculiar e da consequente sobrevalorização das medidas de distância e implicações nos modelos propostos, também foi excluído da base Fernando de Noronha, o que reduziu o total de municípios para 5.506. A reconfiguração das Rls está representada na Figura 2, que identifica as 11 divisões regionais que compõem o primeiro nível hierárquico

FIGURA 2

Regiões de Influência direta das principais metrópoles brasileiras

Regic - 1997

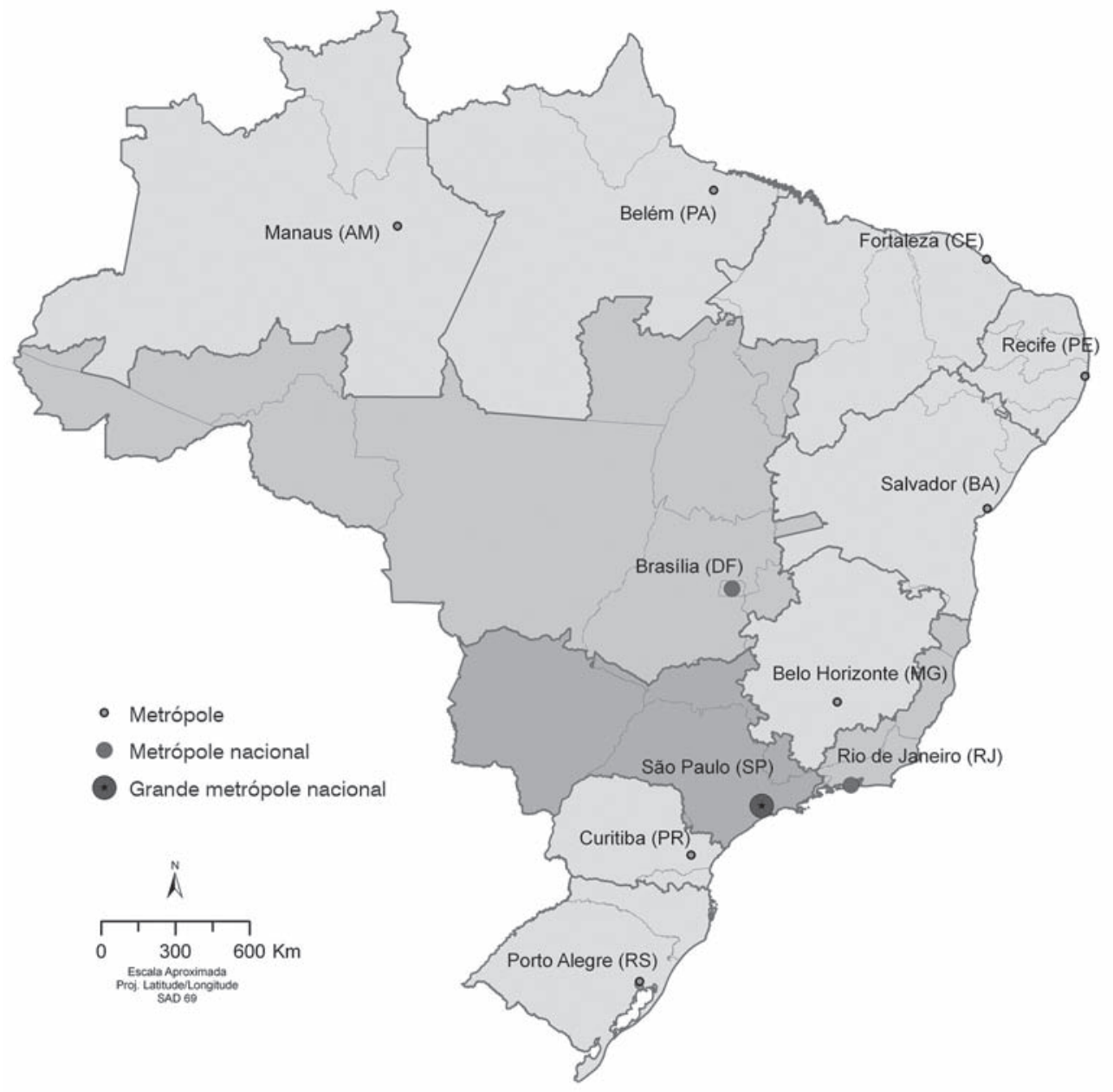

Fonte: Adaptado de IBGE (2008). 
estabelecido nas Regics 2007 (Regiões Metropolitanas).

Em posição hierárquica superior na rede de influência destaca-se a Regic de São Paulo, polarizada pela Grande Metrópole Nacional, envolvendo, além do próprio Estado de São Paulo, o sul de Minas Gerais, o Triângulo Mineiro e o Estado de Mato Grosso do Sul. Com base nos dados do Censo Demográfico e na divisão política administrativa de 2000, essa Regic compreende um conjunto de 847 municípios, que representam $15,38 \%$ do total e abrigam $24,56 \%$ dos residentes no território nacional.

Esse recorte espacial das Regiões de Influência elaborado pelo IBGE (2008), sobreposto à divisão político-administrativa de 2000, que compreendia um total de 5.507 municípios (exceto Fernando de Noronha), serviu de base para as tabulações e análise de dados. Mais que isso, essa regionalização permitiu avaliar a suposta dispersão espacial da população no interior das Regiões de Influência, tendo como ponto de inflexão as respectivas Regiões de Influência. Essa atualização metodológica, ainda que possa suscitar ressalvas e limitações, oferece um retrato mais próximo das relações de interdependência que se estabelecem no espa- ço, onde os volumes e fluxos da população são especialmente relevantes.

\section{Os fluxos migratórios nas Regics metropolitanas: algumas evidências empíricas}

Um dos sinais de dispersão espacial da população brasileira pode ser identificado pelos fluxos migratórios intermunicipais, a partir da avaliação das entradas e saídas de população nas principais regiões metropolitanas do país. Foram considerados os fluxos migratórios de Data Fixa, ${ }^{9}$ compreendidos nos períodos 1986-1991 e 1995-2000, que envolviam os imigrantes ou emigrantes em cada uma das RMs, divididos entre os fluxos inter e intrarregionais. Em uma primeira aproximação, quando analisadas as trocas de população entre as RMs e as demais Regics metropolitanas, denominadas de fluxos inter-Regics, pelo menos dois grupos regionais podem ser identificados (Tabela 1). Um deles compreende a dinâmica observada na Região de Influência de São Paulo (Risp). Quando comparados os dois quinquênios, a RMSP destacava-se como a principal área de atração de população. Em cada um desses períodos, cerca de $600 \mathrm{mil}$

TABELA 1

Fluxos migratórios procedentes das Regiões Metropolitanas para os municípios de outra Regic (fluxos inter-Regics)

Migração de Data Fixa - 1986/1991-1995/2000

\begin{tabular}{|c|c|c|c|c|c|c|}
\hline \multirow{2}{*}{ RMs } & \multicolumn{3}{|c|}{$1986 / 1991$} & \multicolumn{3}{|c|}{$1995 / 2000$} \\
\hline & Entradas & Saídas & Saldo & Entradas & Saídas & Saldo \\
\hline São Paulo & 644.555 & 272.606 & 371.949 & 591.578 & 373.862 & 217.716 \\
\hline Rio de Janeiro & 164.465 & 150.376 & 14.089 & 180.936 & 149.430 & 31.506 \\
\hline Brasília & 483.278 & 259.601 & 223.677 & 435.286 & 264.478 & 170.808 \\
\hline Manaus & 37.974 & 11.636 & 26.338 & 53.278 & 21.568 & 31.710 \\
\hline Belém & 141.295 & 99.969 & 41.326 & 123.314 & 126.948 & -3.635 \\
\hline Fortaleza & 159.091 & 438.922 & -279.831 & 215.423 & 444.135 & -228.711 \\
\hline Recife & 192.884 & 399.744 & -206.860 & 216.018 & 405.306 & -189.288 \\
\hline Salvador & 184.474 & 382.986 & -198.513 & 228.074 & 457.334 & -229.259 \\
\hline Belo Horizonte & 173.232 & 303.217 & -129.985 & 208.159 & 269.442 & -61.283 \\
\hline Curitiba & 226.448 & 385.503 & -159.055 & 223.580 & 268.892 & -45.312 \\
\hline Porto Alegre & 125.960 & 155.413 & -29.452 & 157.394 & 161.072 & -3.678 \\
\hline
\end{tabular}

Fonte: IBGE. Censos Demográficos de 1991 e 2000 (dados da amostra).

\footnotetext{
9 Conforme Carvalho e Rigotti (1998), o migrante de data fixa é definido como a pessoa que residia, no início e ao final do quinquênio considerado, em locais diferentes. No Censo de 2000 essas datas referem-se a 1995 e 2000.
} 
imigrantes, vindos das diversas regiões do país, encaminharam-se para esta região. Contudo, nota-se também um expressivo aumento no número de emigrantes: no período 1995-2000, mais de 373 mil deixaram a RMSP, enquanto no quinquênio anterior esse volume correspondeu a pouco menos de 273 mil, significando um incremento de mais de 100 mil pessoas nessa corrente migratória. Ainda que esse volume tenha relação direta com o estoque da população residente em cada um dos levantamentos censitários e, por consequência, com o crescimento demográfico verificado nesse intervalo, a diferença entre as entradas e saídas de população, nos dois quinquênios, ainda indicava um saldo migratório bruto positivo, o que dava sustentação aos níveis de crescimento demográfico positivos, ainda que baixos.

Em situação oposta destacavam-se as grandes regiões metropolitanas do Nordeste brasileiro, que mantinham um alto saldo migratório negativo, resultante de uma emigração elevada. Esse quadro, quando comparado aos saldos migratórios da metrópole paulista, em boa medida, reflete as trocas diretas de população, ainda marcadas pelo histórico fluxo de migrantes que se deslocavam das RMs de Fortaleza, Recife e Salvador para o Sudeste, destacadamente para a RMSP. Cada uma das Regiões Metropolitanas de Fortaleza, Recife e Salvador perdeu mais de 400 mil migrantes no quinquênio 1995-2000. Nesse mesmo período, essas RMs ostentavam saldo migratório negativo em torno de 200 mil pessoas. As Regiões Metropolitanas de Belo Horizonte, Curitiba e Porto Alegre também apresentaram saldos negativos no quinquênio 1995-2000, porém, os valores foram menos expressivos e inferiores àqueles verificados no período anterior, fruto, em boa medida, da redução no volume da emigração.

No que se refere aos fluxos migratórios no interior da mesma Regic, que envolvem mais diretamente os propósitos desse trabaIho, o quadro é distinto. Nos dois quinquênios avaliados, o saldo da RMSP manteve-se negativo e consideravelmente elevado, resultado direto do sensível crescimento no volume de emigrantes. Como pode ser observado na Tabela 2, no intervalo 19861991 cerca de 410 mil pessoas emigraram da RMSP para sua Região de Influência. Em 1995-2000, o volume desse fluxo atingia mais de meio milhão de migrantes. Nesse mesmo período, o número de imigrantes na RMSP foi inferior a 150 mil. Por outro lado, com exceção das RMs do Rio de Janeiro e de Brasília, que também exibiam saldos negativos, as demais RMs analisadas apresentavam saldo positivo nos dois períodos. No entanto, mesmo que essas regiões funcionassem como núcleos de atração de população em suas respectivas Regiões de Influência, o número

TABELA 2

Fluxos migratórios entre as Regiões Metropolitanas e os municípios da mesma Regic (fluxos intra-Regic) Migração de Data Fixa - 1986/1991-1995/2000

\begin{tabular}{|c|c|c|c|c|c|c|}
\hline \multirow{2}{*}{ RMs } & \multicolumn{3}{|c|}{$1986 / 1991$} & \multicolumn{3}{|c|}{$1995 / 2000$} \\
\hline & Entradas & Saídas & Saldo & Entradas & Saídas & Saldo \\
\hline São Paulo & 124.526 & 419.329 & -294.803 & 142.783 & 510.260 & -367.477 \\
\hline Rio de Janeiro & 60.736 & 107.527 & -46.791 & 70.522 & 135.482 & -64.960 \\
\hline Brasília & 39.946 & 74.360 & -34.414 & 48.035 & 114.159 & -66.124 \\
\hline Manaus & 24.468 & 13.100 & 11.368 & 36.871 & 30.575 & 6.296 \\
\hline Belém & 69.329 & 31.989 & 37.340 & 74.900 & 52.217 & 22.684 \\
\hline Fortaleza & 137.316 & 41.847 & 95.469 & 95.655 & 60.349 & 35.306 \\
\hline Recife & 84.726 & 43.235 & 41.490 & 70.342 & 49.030 & 21.312 \\
\hline Salvador & 111.880 & 52.045 & 59.835 & 108.251 & 70.901 & 37.349 \\
\hline Belo Horizonte & 145.143 & 62.638 & 82.505 & 152.081 & 75.126 & 76.955 \\
\hline Curitiba & 125.602 & 41.323 & 84.279 & 140.653 & 60.587 & 80.066 \\
\hline Porto Alegre & 165.872 & 87.068 & 78.804 & 144.252 & 106.932 & 37.320 \\
\hline
\end{tabular}

Fonte: IBGE. Censos Demográficos de 1991 e 2000 (dados da amostra). 
absoluto de imigrantes foi reduzido quando comparados os dois quinquênios. Muito mais relevante, entretanto, foi o crescimento na emigração metropolitana, observado em todas as Regics.

Novamente, a notoriedade dos fluxos migratórios na Regic de São Paulo chama atenção. De 1995 a 2000, como resultado das trocas de migrantes com a RMSP, foram verificados ganhos de população em grande parte dos municípios de sua Região de Influência. Como representado na Figuras 3, de um total de 808 municípios que integravam a Região de Influência de São Paulo (Risp), mais de $89 \%$ (722) exibiram saldo positivo. No quinquênio anterior eram 626 municípios nessa condição. Em apenas alguns municípios localizados no Triângulo Mineiro e ao sul de Mato Grosso do Sul foram observados saldos migratórios negativos. No entanto, mesmo nesses espaços, bastante diferenciados geograficamente, com características físicas peculiares, como relevo, clima, hidrografia, etc., os vínculos com a metrópole paulista também configuram campos de atração de população.

Quando avaliados os vetores migratórios que representam os deslocamentos espaciais da população, nota-se um aumento generalizado no número de municípios que receberam emigrantes das respectivas regiões metropolitanas. Mesmo que boa parte do crescimento no número seja consequência direta do aumento de municípios emancipados entre os dois Censos, a intensificação da emigração procedente das RMs (número de vetores e volume de migrantes) sugere um rearranjo na dinâmica migratória regional do país. O caso da RM de São Paulo, cujos volumes são mais expressivos, novamente deve ser mencionado. No período 1995-2000, 788 municípios da Risp receberam emigrados da $\mathrm{RM}$, enquanto no intervalo anterior eram 702. Em alguns casos, como na Regic de Porto Alegre, o crescimento no número de vetores foi ainda mais significativo, elevando-se de 387, em 1986-1991, para 510 municípios, em 1995-2000.

FIGURA 3

Saldo migratório nas trocas entre os municípios da Risp e a RM $1986 / 1991-1995 / 2000$

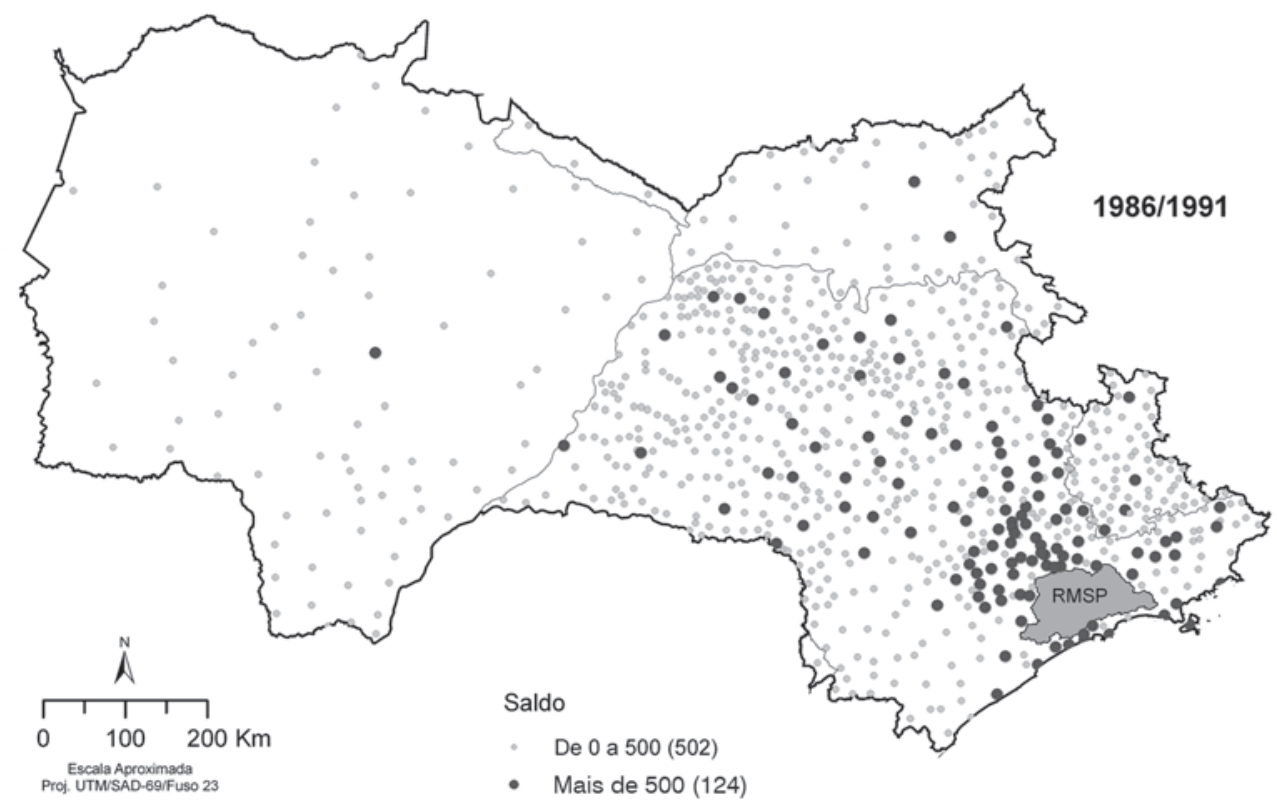

(continua) 


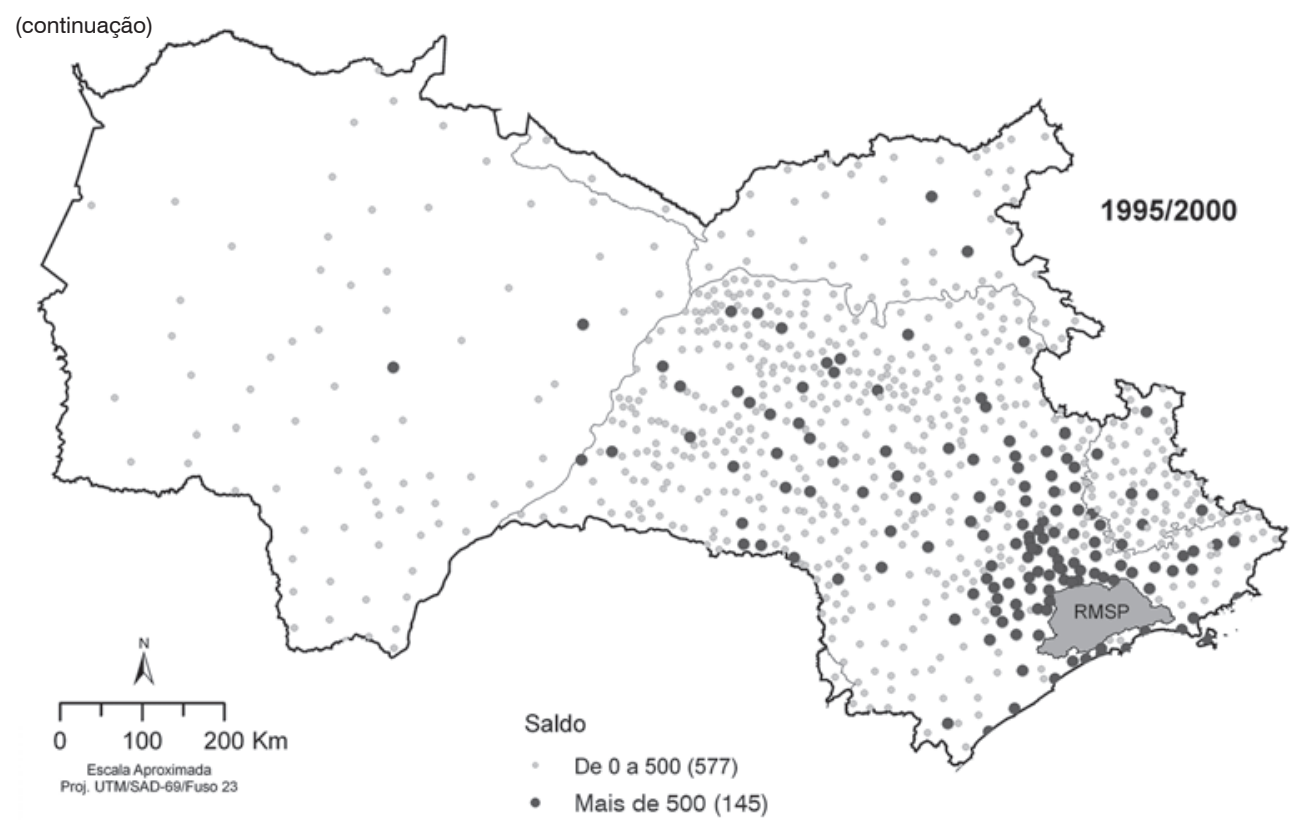

Fonte: IBGE. Censos Demográficos de 1991 e 2000 (dados da amostra).

Mesmo que o aumento na frequência de vetores de emigração das RMs para suas respectivas Regiões de Influência pudesse confirmar uma nítida dispersão espacial da população, os valores referentes à distância média ponderada não corroboram de imediato essa tendência. ${ }^{10}$ Excluídos os casos do Rio de Janeiro, Manaus, Salvador e Curitiba, na maior parte das Regics verificou-se redução na distância dos fluxos migratórios procedentes das respectivas RMs nos quinquênios 1986-1991 e 1995-2000. Também cabe destacar os casos do Rio de Janeiro e Manaus, que exibiam os valores de distância mais elevados (todos com média superior a $300 \mathrm{~km}$ ). Mesmo que os valores referentes às distâncias médias permanecessem elevados no caso da RMSP, foi observada pequena redução quando comparados os dois períodos $(372,79 \mathrm{~km}$ em 1986-1991 e 366,77 km em 1995-2000).

Algumas observações devem ser consideradas na interpretação desses indicadores, notadamente nos casos de redução dos escores relativos à distância. ${ }^{11} \mathrm{~A}$ análise de dados, discriminados em três Regiões de Influência (RI-1, RI-2 e RI-3), ${ }^{12}$ conforme tercis de distância em relação ao núcleo me-

\footnotetext{
10 O peso foi atribuído de acordo com o número de imigrantes de cada vetor. Dessa forma, na distância média dos fluxos migratórios que envolvem os emigrantes de uma determinada RM para os municípios de sua Região de Influência, foi utilizado o volume de migrantes de cada um dos vetores como fator de ponderação, dadas as respectivas distâncias.

11 É oportuno mencionar que vários aspectos geográficos dessas Regiões de Influência explicam, direta ou indiretamente, possibilidades de trajetórias migratórias articulando distâncias variadas entre origem e destino. Nas Regiões de Influência com vários municípios localizados na faixa litorânea, por exemplo, há interferência de atributos relativos às condições morfoclimáticas, aos recursos naturais disponíveis e a fatores culturais. Já nos espaços interioranos, também há barreiras físicas similares e/ou específicas que podem restringir e/ou favorecer a imigração.

12 Tendo como base o recorte cartográfico referente à divisão político-administrativa de 2000, adotado no Censo Demográfico de 2000 , utilizaram-se como referência as coordenadas geodésicas de referência da sede municipal do core metropolitano, de acordo com critérios estabelecidos pelo próprio IBGE. A partir desse ponto, para cada uma das Regics, foram identificadas as distâncias em linha reta em relação à sede de cada município. O conjunto desses valores permite agrupar os municípios de cada Regic conforme tercis de distâncias, denominados de Rl-1, Rl-2 e Rl-3 (o primeiro é formado pelos municípios mais próximos do Core Metropolitano e o último pelos mais distantes). Dessa forma, cada uma das Rls compreende aproximadamente 1/3 dos municípios de cada Regic em 2000. Por exemplo, na Regic de São Paulo, as sub-regiões Rl-1, RI-2 e RI-3 possuem 270, 269 e 269 municípios, respectivamente. As distâncias em relação a São Paulo são obtidas pelos seguintes raios de circunferência: Rl-1 $\Rightarrow$ até $240,32 \mathrm{~km}$; RI-2 $\Rightarrow$ de 240,33 km a 453,52 Km; e a Rl-3 $\Rightarrow$ mais de 453,53 km.
} 
TABELA 3

Número de vetores e distância média dos fluxos de migrantes das Regiões Metropolitanas com destino aos municípios da mesma RI 1986/1991-1995/2000

\begin{tabular}{|c|c|c|c|c|}
\hline \multirow{2}{*}{ RMs } & \multicolumn{2}{|c|}{ № de vetores } & \multicolumn{2}{|c|}{ Distância média ponderada (em Km) } \\
\hline & $1986 / 1991$ & $1995 / 2000$ & 1986/1991 & $1995 / 2000$ \\
\hline São Paulo & 702 & 788 & 372,79 & 366,77 \\
\hline Rio de Janeiro & 221 & 246 & 378,16 & 386,21 \\
\hline Brasília & 267 & 330 & 94,59 & 82,16 \\
\hline Manaus & 51 & 68 & 170,70 & 300,29 \\
\hline Belém & 96 & 135 & 290,46 & 256,15 \\
\hline Fortaleza & 230 & 291 & 122,53 & 115,79 \\
\hline Recife & 293 & 337 & 105,86 & 98,54 \\
\hline Salvador & 359 & 399 & 105,82 & 123,43 \\
\hline Belo Horizonte & 417 & 519 & 119,13 & 110,20 \\
\hline Curitiba & 279 & 353 & 109,09 & 122,51 \\
\hline Porto Alegre & 387 & 510 & 183,65 & 164,86 \\
\hline
\end{tabular}

Fonte: IBGE. Censos Demográficos de 1991 e 2000 (dados da amostra).

tropolitano, em vários casos, indica aumento no volume da população migrante que se dirigiu às áreas mais próximas da Região Metropolitana, o que alimentou a redução das médias de distância dos movimentos migratórios. Em todas as Regics, nos dois quinquênios estudados, mais da metade dos emigrados das RMs encaminhou-se para a sub-região RI-1. Em Brasília e Fortaleza, por exemplo, a proporção de emigrantes que se dirigiram para a $\mathrm{Rl}-1$, nos dois quinquênios, foi superior a $90 \%$.

Ainda que fosse esperado um maior volume de migrantes com destino a essa Rl-1, tendo em vista a predominância da migração de curta distância, como já descrita por Ravenstein (1980), acrescenta-se o fato de também ter ocorrido, em todas as Regics, exceto as de Belo Horizonte e Manaus, um crescimento absoluto e relativo no número de imigrantes procedentes das RMs. ${ }^{13} \mathrm{Na}$ RMRJ, em 1995-2000, dos 135.482 emigrados, 85.456 dirigiram-se para a $\mathrm{Rl}-1$, o que correspondia a $63,08 \%$ do total. No quinquênio anterior, essa proporção era de $52,68 \%$. No caso de São Paulo, os migrantes que tiveram como destino a Rl-1 passaram de $62,84 \%$, em 1986-1991, para 68,19\%, em 1995-2000, o que perfaz 347.957 pessoas de um universo de 510.260 emigrantes da RM com destino a toda a RI, nesse último quinquênio. ${ }^{14}$

A Regic de São Paulo é emblemática não apenas pelo volume expressivo do contingente envolvido, mas também pela consolidação de uma rede de cidades de médio e grande portes, fortemente vinculada à Região Metropolitana, onde os fluxos migratórios conferem a materialidade densa da rede. Como pode ser observado na Figura 3, boa parte dos municípios que mais receberam emigrados da RMSP pertencia à $\mathrm{Rl}-1$, definida pelo limite de 240,32 km. Em 1995-2000, dos 18 municípios com mais de 5 mil imigrantes procedentes da RMSP, 14 localizavam-se na RI-115 (Figura 4): Atibaia,

\footnotetext{
${ }^{13}$ Nesses dois casos, a pequena queda na proporção de migrantes metropolitanos na RI-1 parece ser reflexo da estrutura e organização espacial da rede de cidades de cada Regic, bem como das características geográficas singulares. Na RI de Belo Horizonte um aspecto que provavelmente influencia essa dispersão da migração associa-se ao fato de que boa parte das capitais regionais localiza-se nas RI-2 e RI-3, que atuam como importantes centros de atração de população. Das seis capitais regionais consideradas pelo IBGE, excluídos os municípios de Uberlândia e Juiz de Fora que integram as Regics de São Paulo e Rio de Janeiro, respectivamente, apenas Divinópolis e Ipatinga compõem a RI-1. Já na RI de Manaus o quadro é ainda mais distinto. Além de uma dispersão relativa à própria estrutura da rede urbana regional, fortemente limitada pelas condições naturais, o principal centro de polarização da RI é Boa Vista (RR), muito além dos $303,82 \mathrm{~km}$ que delimitam a Rl-1 Manaus.

14 Mais detalhes ver Lobo (2009).

15 No quinquênio anterior (1986/1991), foram nove municípios da RI-1 que receberam mais de 5 mil emigrados da RMSP.
} 
FIGURA 4

Emigração da RMSP para as Regiões de Influência de São Paulo RI-1, RI-2 e RI-3

1986/1991-1995/2000

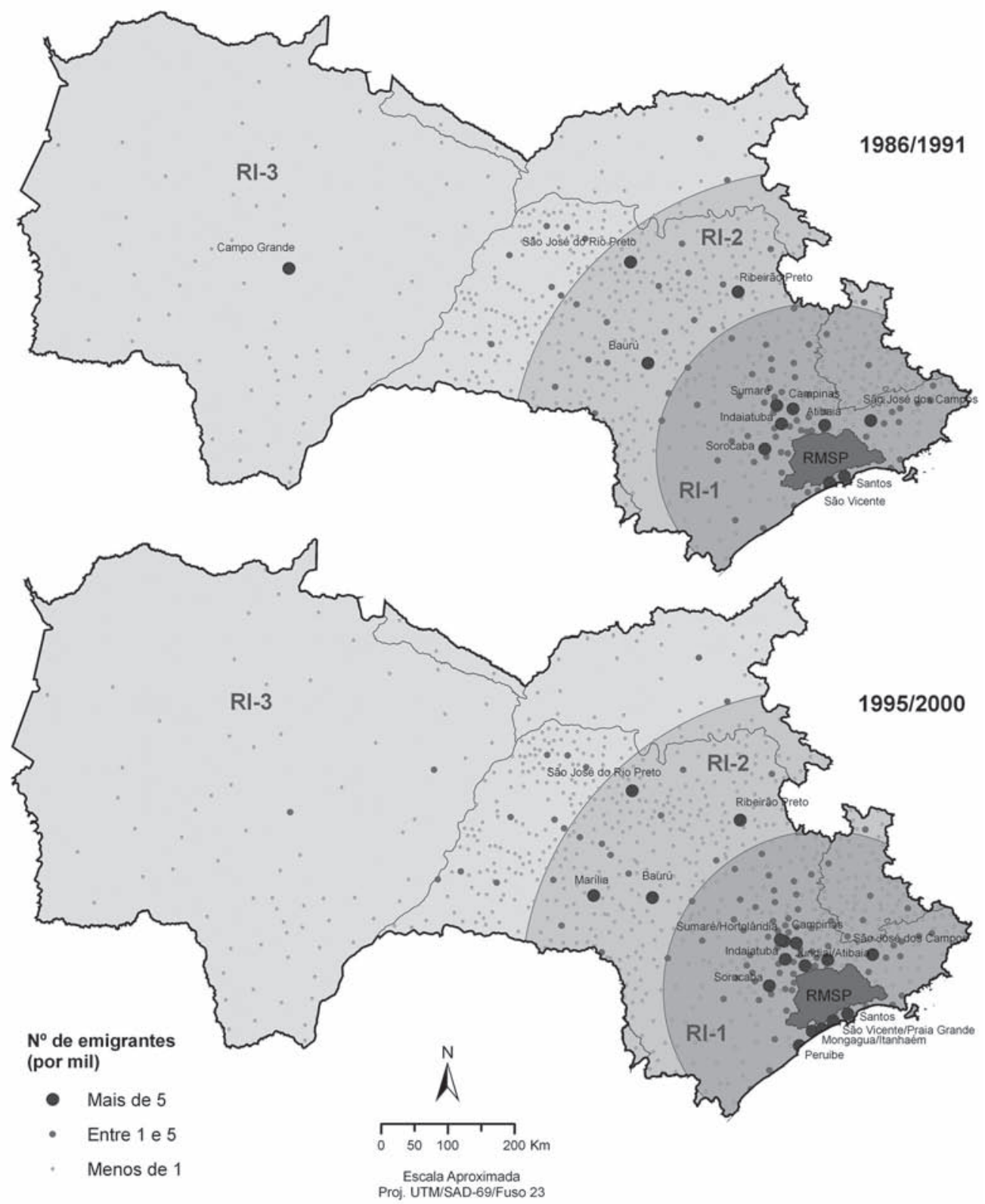

Fonte: IBGE. Censos Demográficos de 1991 e 2000 (dados da amostra). 
Campinas, Hortolândia, Indaiatuba, Itanhaém, Jundiaí, Mongaguá, Peruíbe, Praia Grande, Santos, São José dos Campos, São Vicente, Sorocaba e Sumaré. Desse grupo, Praia Grande, Campinas, Sorocaba e São José dos Campos foram aqueles que mais atraíram população, todos com mais de 10 mil imigrantes. Em vários aspectos, a intensificação da emigração metropolitana sugere a alusão a uma das fases do modelo apresentado por Richardson (1980), quando da redistribuição da população ao longo do sistema urbano, refletindo as vantagens relativas das cidades secundárias. São exatamente essas cidades secundárias, apontadas por Redwood III (1984), que cumprem função crucial na eficiência econômica e no desenvolvimento regional.

\section{Considerações finais}

Ainda existem inúmeras incertezas acerca de determinados padrões de distribuição espacial da população brasileira. A crença na suposta reversão da polarização, ou mesmo de desconcentração espacial, como sugerida por determinados autores e proposta nos modelos clássicos da economia regional, tem se mostrado inapropriada à análise do caso brasileiro. Contudo, a progressiva queda relativa no peso econômico e demográfico dos principais centros urbanos do país, bem como a desaceleração no ritmo de crescimento populacional das principais Regiões Metropolitanas, requer um maior aprofundamento na avaliação de novas tendências e padrões na distribuição espacial da população brasileira.

As últimas três décadas do século passado são centrais na análise da dinâmica demográfica brasileira. Se a progressiva queda nas taxas de fecundidade foi responsável direta pela forte desaceleração no ritmo de crescimento demográfico do país, as migrações internas foram fundamentais no processo de redistribuição espacial da população. A partir da década de 1970 , acumulam-se evidências acerca da redução do peso relativo das metrópoles. Mesmo que as metrópoles e suas Regiões de Influência continuem atraindo expressivos contingentes, a intensificação nos fluxos de emigrantes tem refletido diretamente no crescimento demográfico de vários núcleos urbanos fora das principais regiões metropolitanas brasileiras, tornando mais densa a rede de cidades em cada uma de suas Regiões de Influência.

Os resultados obtidos nesta pesquisa não confirmam a integralidade da reversão da polarização nos termos de Richardson (1980), nem a suposta desconcentração econômico-demográfica destacada por Redwood III (1984), entre outros, mas oferecem sinais de dispersão espacial da população, já proeminente em determinados casos, como na Região de Influência de São Paulo.

Mesmo que as maiores regiões metropolitanas brasileiras tenham mantido sua centralidade regional, o que torna equivocado falar em desconcentração absoluta, o crescimento demográfico acelerado de vários pontos na rede urbana brasileira que têm se destacado na atração de migrantes indica uma redistribuição espacial da população no interior das Regiões de Influência das principais metrópoles do país.

No caso da Região de Influência de São Paulo, que se mantém como principal centro de atração de imigrantes do país, os efeitos dessa dispersão espacial da população mostram-se mais consolidados, sobretudo no interior da rede de cidades mais próximas à capital. A denominada Região de Influência 1 (RI-1) compreende muitos municípios que têm atraído um crescente número de pessoas que deixaram a RMSP. $O$ volume desses fluxos direcionados para os principais polos de atração nessa região foi tão expressivo que reduziu os valores de distância ponderada, o que sugere tratar-se de uma forma de dispersão polinucleada (LOBO, 2009), por onde se observam claros sinais de expansão no interior da Região de Influência, para além dos modestos $150 \mathrm{~km}$ do campo aglomerativo de Azzoni (1986).

Essas evidências, ainda que circunscritas aos fluxos migratórios ocorridos nas décadas de 1980 e 1990, dada a conjuntura econômica e condições sociais específicas, sugerem a necessidade de revisão dos conceitos de centro e periferia, tal como tradicionalmente empregado na literatura. A centralidade regional restrita ao core metro- 
politano já não é suficiente à compreensão adequada da organização do espaço regional. Uma revisão conceitual pode facilitar um melhor entendimento da possível dispersão espacial. Conceitos tradicionalmente aplicados na análise urbana, como dispersão urbana, conurbação, megalópole, adaptados à análise regional, devem ser requalificados diante das formações em rede.

Outra conclusão deste trabalho refere-se à necessidade de se explorarem as ferramentas oferecidas pela análise espacial, ainda pouco utilizadas na Economia, na Demografia ou mesmo na Geografia. Os indicadores elaborados e expostos, tendo como base a variável distância, são exemplos das possibilidades oferecidas às pesquisas nas áreas de Ciências Humanas e Ambientais. Acrescenta-se, a essas potencialidades, uma das vocações da Geografia: os estudos regionais. O recorte espacial

\section{Referências}

AZZONI, C. Indústria e reversão da polarização no Brasil. Ensaios Econômicos, São Paulo, IPE/USP, n. 58, 1986.

BAENINGER, R. A nova configuração no Brasil: desaceleração metropolitana e redistribuição da população. In: XI ENCONTRO DE ESTUDOS POPULACIONAIS, 11, 1998, Caxambu. Anais... Caxambu: Associação Brasileira de Estudos Populacionais, v. 1, p. 729-772, 1998.

BRITO, F. O deslocamento da população brasileira para as metrópoles. Estudos Avançados, São Paulo, v. 20, n. 57, p. 221236, maio/ago. 2006.

. Mobilidade espacial e expansão urbana: o caso da Região Metropolitana de Belo Horizonte. In: X ENCONTRO DE ESTUDOS POPULACIONAIS, 10, 1997, Brasília. Anais... Brasília: Associação Brasileira de Estudos Populacionais, v. 2, p. 771-788, 1997.

CANO, W. Raízes da concentração industrial em São Paulo. 4. ed. Campinas: Instituto de Economia da Unicamp, 1998.

Questão regional e urbanização no desenvolvimento econômico brasileiro oferecido pelas Regiões de Influência das Cidades, proposto pelo IBGE, ainda que possa ser criticado e contestado em relação aos conceitos e elementos metodológicos utilizados, permite uma análise diferenciada das tradicionais abordagens desenvolvidas pela Economia.

Também deve ser destacada a importância, notadamente para a Geografia da População e os estudos sobre migrações, de se explorarem as bases de dados extraídas de fontes como o Censo Demográfico, já recorrentemente utilizado pela Demografia. Essa possibilidade ganha relevância tendo em vista a aproximação do Censo de 2010. Novas evidências podem ser trazidas à luz, confirmando ou não determinadas tendências ou indícios observados nesse trabalho, que reúne evidências empíricas relativas às duas últimas décadas do século passado.

pós 1930. In: IV ENCONTRO DE ESTUDOS POPULACIONAIS, 4, 1988, Olinda. Anais... Olinda: Associação Brasileira de Estudos Populacionais, p. 67-100, 1988.

CARVALHO, J. A. M.; RIGOTTI, J. I. Análise das metodologias de mensuração das migrações. In: ENCONTRO NACIONAL SOBRE MIGRAÇÃO, 1998, Curitiba. Anais... Curitiba: Ipardes/Abep, 1998.

CORRÊA, R. L. Estudos sobre a rede urbana. Rio de Janeiro: Bertrand Brasil, 2006. Identificação dos centros de gestão do território no Brasil. Revista Brasileira de Geografia, Rio de Janeiro, IBGE, v. 57, n. 1, p. 83-102, jan./mar.1995.

DINIZ, C. C. Desenvolvimento poligonal no Brasil; nem desconcentração, nem contínua polarização. Nova Economia - Revista de Ciências Econômicas da UFMG, Belo Horizonte, v. 31, n. 11, p. 35-64, set. 1993.

HADDAD, P. Economia regional: teorias e métodos de análise. Recife: Banco do Nordeste do Brasil, 1980.

INSTITUTO BRASILEIRO DE GEOGRAFIA E ESTATÍSTICA - IBGE. Disponível em: 
<http://www.ibge.gov.br/>. Acesso em: 10 mar. 2009.

Região de influência das cidades 2007. Rio de Janeiro: IBGE. 2008. Disponível em: <http://www.ibge.gov.br/home/ geociencias/geografia/regic.shtm?c=6/> Acesso em: 10 mar. 2009.

LEE, E. S. Uma teoria sobre migração. In: MOURA, H. (Coord.). Migração interna: textos selecionados. Fortaleza: BNB, Etene, 1980, p. 89-114.

LO, F.; SALIH, K. Growth poles, agropolitan development and polarization reversal: debate and search for aternatives. In: STOHR, W.; TAYLOR, D. Development from about or from below? The dialetics of regional plane in developing countries. New York: John Wiley \& Sons, 1991, p. 123-152.

LOBO, C. Dispersão espacial da população nas Regiões de Influência das principais metrópoles brasileiras. Tese (Doutorado em Geografia), Instituto de Geociências, Universidade Federal de Minas Gerais, Belo Horizonte, 2009.

MARTINI, G.; CAMARANO, A. A.; NEUPERT, R.; BELTRÃO, K. A urbanização no Brasil: retrospectiva, componentes e perspectiva. In: VI ENCONTRO DE ESTUDOS POPULACIONAIS, 6, 1988, Olinda. Anais... Olinda: Associação Brasileira de Estudos Populacionais, v. 1, p. 19-65, 1988.

MARTINE, G. A redistribuição espacial da população brasileira durante a década de 80. Brasília: Ipea, 1994 (Textos para discussão, 329).

MATOS, R. (Org.). Espacialidades em rede: população, urbanização e migração no Brasil contemporâneo. Belo Horizonte: C/Arte, 2005.

O Brasil dividido e a rede urbana fracionada. Cadernos do Leste, Belo Horizonte, IGC/UFMG, v. 1, n. 1, p. 1-51, 2003.

Migração e desconcentração demográfica nas principais áreas de atração populacional de Minas Gerais. In: XI ENCONTRO DE ESTUDOS POPULACIONAIS, 11, 1998, Caxambu. Anais... Caxambu:
Associação Brasileira de Estudos Populacionais, v. 1, p. 713-728, 1998.

Dinâmica migratória e desconcentração da população na macrorregião de Belo Horizonte. Tese (Doutorado em Demografia) - Centro de Desenvolvimento e Planejamento Regional, Faculdade de Ciências Econômicas, Universidade Federal de Minas Gerais, Belo Horizonte, 1995a.

Questões teóricas acerca dos processos de concentração e desconcentração da população no espaço. Revista Brasileira de Estudos de População, São Paulo, p. 35-58, 1995b.

MATOS, R.; BAENINGER, R. Migração e urbanização no Brasil: processos de concentração e desconcentração espacial e o debate recente. Cadernos do Leste, Belo Horizonte, IGC/UFMG, v. 6, n. 6, p. 7-44, 2004.

MATOS, R.; LOBO, C.; STEFANI, J. Inversão no balanço migratório mineiro: as trocas populacionais entre Minas e São Paulo. In: XIV ENCONTRO DE ESTUDOS POPULACIONAIS, 14, 2004, Caxambu. Anais... Caxambu: Associação Brasileira de Estudos Populacionais, v. 1, p. 1-17, 2004.

NEGRI, B. Concentração e desconcentração industrial em São Paulo (1880-1990). Campinas: Ed. Unicamp, 1996.

PACHECO, C. A.; PATARRA, N. Movimentos migratórios anos 80: novos padrões? In: PATARRA, N. (Org.). Migração, condições de vida e dinâmica urbana. Campinas: Unicamp, 1997, p. 25-72.

RAVENSTEIN, E. G. Leis da migração. In: MOURA, $H$. (Coord.). Migração interna: textos selecionados. Fortaleza: BNB, Etene, 1980 , p. $22-88$.

REDWOOD III, J. Reversion de polarizacion, ciudades secundarias y eficiencia en el desarrollo nacional: una vison teorica aplicada al Brasil contemporaneo. Revista Latinoamericana de Estudios Urbanos Regionales, Santiago, v. 11, n. 32, dic. 1984.

RENNER, C. H.; PATARRA, N. Migrações. In: SANTOS, J. L. F.; LEVY, M. S. F.; SZMRECSÁNYI, T. (Orgs.). Dinâmica da população: teoria, métodos e técnicas de 
análise. São Paulo: T. A. Queiroz, 1991, p. 209-235.

RICHARDSON, H. W. Polarization reversal in developing countries. The Regional Science Association Papers, Los Angeles, v. 45, p. 67-85, Nov. 1980.

RIGOTTI, J. I. R. Técnicas de mensuração das migrações a partir de dados censitários: aplicação aos casos de Minas Gerais e São Paulo. Tese (Doutorado em Demografia) - Centro de Desenvolvimento e Planejamento Regional, Faculdade de Ciências Econômicas, Universidade Federal de Minas Gerais, Belo Horizonte, 1999.
SANTOS, M. A natureza do espaço: técnica e tempo, razão e emoção. 2. ed. São Paulo: Hucitec, 1997.

SINGER, P. Economia política da urbanização. São Paulo: Hucitec, 1973.

TOWNROE, P.; KEEN, D. M. Polarization reversal in the state of São Paulo, Brazil. Journal of the Regional Studies Association, Cambridge, v. 18, n. 1, Feb. 1984.

UNITED NATIONS. Principles and Recommendations for Population and Housing Censuses, Revision 2. New York, 2008.

\section{Resumen}

Migraciones y dispersión espacial de la población en las regiones de influencia de las principales metrópolis brasileñas

La segunda mitad del siglo pasado es muy importante en el análisis de la distribución espacial de la población brasileña. En pocos años, ante el proceso de urbanización e industrialización del país, resultado en buena medida de la dinámica migratoria interna, gran parte de la población y de las actividades económicas pasaron a concentrarse en los principales centros urbanos, sobre todo en las grandes aglomeraciones urbanas. No obstante, desde el final de la década de los 70, algunos autores ya vislumbraban la hipótesis de reversión de la polarización en Brasil, tal como se formulaba en los modelos aplicados en los países desarrollados. Aparte de las recurrentes controversias sobre el tema, que conllevaron la difusión de expresiones como "reversión de la polarización", "desconcentración concentrada", "desarrollo poligonal", entre otras, esta investigación tiene como objetivo principal evaluar la actual magnitud de la dispersión espacial de la población brasileña, teniendo como base las regiones de influencia de las principales metrópolis del país, según la información publicada por el IBGE. Para ello, se utilizaron las bases de datos, referentes a los censos demográficos de 1991 y 2000, que posibilitaron identificar los flujos de población. Incluso si los resultados no son conclusivos para todas las regiones de influencia, en el caso específico de São Paulo los valores para las reservas y flujos, asociados a la dimensión distancia, indican la intensificación en la ocupación de espacios fuera de los límites de las regiones metropolitanas. El crecimiento de la emigración hacia la región de influencia de la metrópoli paulista parece confirmar una especie de "dispersión polinuclear", observándose claras señales de expansión hacia el interior de la región de influencia, lo que sugiere el fortalecimiento de determinados centros regionales y un mayor dinamismo de la economía local.

Palabras-clave: Migración. Dispersión espacial. Regiones de Influencia.

\section{Abstract}

Migrations and spatial dispersion of the population throughout areas of influence in the main metropolitan regions in Brazil

An understanding of the second half of the 20th century is essential to any analysis of the spatial distribution of the Brazilian population. As part of a nationwide process of urbanization 
and industrialization, a large part of the population and its economic activities moved to the country's metropolitan areas in just a few years. This process resulted largely from the dynamics of internal migrations, but since the late 1970s a number of authors have posited the hypothesis of a reversal in the polarization in Brazil, as described in models applied in developed countries. It is true that recurrent controversies on the subject have brought to the fore expressions such as "reversion of polarization," "concentrated deconcentration, and "polygonal development." The main objective of this study is to appraise the current magnitude of the spatial dispersion of the Brazilian population, based on areas of influence that surround the country's largest metropolitan regions, as defined by the Brazilian Census Office (IBGE). The research was based on the 1991 and the 2000 Demographic Censuses, which made it possible to identify the migratory flows of the population. In general, the results were inconclusive for all the regions of influence. Nonetheless, in the specific case of São Paulo, the data related to inventories and flows, associated with the dimension of distance, indicate intensification in the occupation of spaces beyond the official boundaries of the metropolitan regions. The increased emigration to the region of influence of São Paulo seems to confirm a type of "polynucleated dispersion" with clear signs of expansion within the region of influence. This would seem to suggest a strengthening of certain regional centers and greater dynamism of local economies.

Keywords: Migration. Spatial dispersion. Regions of Influence.

Recebido para publicação em 30/10/2009. Aceito para publicação em 28/05/2010. 
